\title{
Effects of periodontal treatment on the medical status of patients with type 2 diabetes mellitus: a pilot study
}

\author{
Joichiro Hayashi ${ }^{1 *}$, Akihiko Hasegawa², Kohei Hayashi ${ }^{1}$, Takafumi Suzuki', Makiko Ishii ${ }^{1}$, Hideharu Otsuka', \\ Kazuhiro Yatabe ${ }^{1}$, Seiichi Goto ${ }^{2}$, Junichi Tatsumi ${ }^{1}$ and Kitetsu Shin ${ }^{1}$
}

\begin{abstract}
Background: Studies have demonstrated that periodontal disease is associated with the development of systemic complications in patients with type 2 diabetes mellitus (T2DM). The purpose of this pilot study was to investigate which markers among various systemic disease parameters are affected by periodontal treatment in patients with T2DM.

Methods: Twelve patients with T2DM were given oral hygiene instructions and subsequent subgingival scaling and root planing. The periodontal status was recorded, and blood and urine samples were taken to measure various parameters of glucose control and systemic status at baseline and 1 month following the periodontal treatment. Serum concentrations of tumor necrosis factor- $a$ and high-sensitivity C-reactive protein were measured by enzymelinked immunosorbent assay.

Results: After the periodontal treatment, the glycated hemoglobin value was significantly improved. The levels of urinary N-acetyl-B-D-glucosaminidase and albumin, which are markers of renal dysfunction, also decreased significantly after treatment. Among the parameters measured in serum, the $\gamma$-glutamyl transpeptidase level, which is usually interpreted as a marker of liver dysfunction, was significantly reduced. The serum concentrations of tumor necrosis factor$a$ and high-sensitivity C-reactive protein were also significantly reduced by periodontal treatment.
\end{abstract}

Conclusion: Within the limitations of this pilot study, periodontal treatment may be effective not only in improving metabolic control, but also in reducing the risk of diabetic kidney and liver disease in patients with T2DM.

Keywords: Type 2 diabetes mellitus, Periodontal treatment, Glycated hemoglobin, Urinary N-acetyl- $\beta$-D-glucosaminidase, Y-glutamyl transpeptidase

\section{Background}

Type 2 diabetes mellitus (T2DM) is a group of metabolic diseases characterized by hyperglycemia resulting from resistance to insulin action and an inadequate compensatory insulin secretory response. The chronic hyperglycemia of diabetes is associated with long-term damage, dysfunction, and failure of various organs.

Periodontitis, a common infectious disease, is regarded as a systemic inflammation. It produces some inflammatory cytokines in the local tissue and increases their circulating

\footnotetext{
* Correspondence: hayashi@dent.meikai.ac.jp

${ }^{1}$ Division of Periodontology, Department of Oral Biology and Tissue

Engineering, Meikai University School of Dentistry, 1-1 Keyakidai, Sakado-shi,

Saitama-ken 350-0283, Japan

Full list of author information is available at the end of the article
}

levels. Some studies have suggested a bidirectional relationship between T2DM and periodontitis [1]. It is known that diabetic patients have an increased risk of periodontitis, and that, once established, their periodontitis is more severe [2]. On the other hand, both direct and indirect evidence supports the concept that periodontal infection adversely affects glycemic control in people with diabetes [3].

Intervention studies examining the effects of periodontal treatment on glycemic control in diabetic patients with periodontal disease have generally shown a beneficial effect, with reduced glycated hemoglobin (HbA1c) levels [4-7], although not all studies confirmed this improvement [8]. Furthermore, some studies have demonstrated that periodontal disease is associated with the 
development of other systemic complications in diabetic patients, such as cardiovascular disease and renal disease [9-12]. However, it is still unclear whether periodontal treatment influences medical status other than glycemic control in such patients. The aim of this pilot study was to investigate which markers among various systemic disease parameters are affected by periodontal treatment in patients with T2DM.

\section{Methods}

\section{Study subjects}

Twelve subjects (mean age: 62.1 years; 7 males and 5 females) diagnosed with type $2 \mathrm{DM}$ and chronic periodontitis were selected from the population referred to the Periodontal Clinic and to Internal Medicine at Meikai University Hospital. Criteria for inclusion were: type 2 DM diagnosed for $>1$ year, no change in DM treatment during the study, and presence of chronic periodontitis. Chronic periodontitis was diagnosed according to the criteria of the American Academy of Periodontology [13]. The exclusion criteria were: $\mathrm{HbA} 1 \mathrm{c} \geq 8 \%$, any form of periodontal treatment in the previous 6 months, pregnancy, bleeding disorders, and any serious systemic diseases. Three subjects were taking prescribed insulin, and four subjects were smokers.

\section{Experimental design and treatment protocols}

The patients received individually tailored intensive oneon-one oral hygiene instruction at several visits. Then, as the standard treatment for periodontitis, scaling and root planing per quadrant were performed using ultrasonic instruments and Gracey curettes (Hu-Friedy, Chicago, IL, USA). The periodontal parameters were recorded at baseline and at the first month following periodontal treatment. The following clinical parameters were recorded: number of teeth, probing depth (PD), and bleeding on probing (BOP). The $\mathrm{PD}$ and $\mathrm{BOP}$ were measured at six sites per tooth (mesio-buccal, mid-buccal, disto-buccal, disto-lingual, mid-lingual, and mesio-lingual). Venous blood and urine samples were taken at baseline and at the 1-month recall visit to monitor glucose control and systemic status. For the metabolic assessment, the blood samples were analyzed for fasting plasma glucose (FPG), immunoreactive insulin (IRI), and HbAlc (National Glycohemoglobin Standardization Program [14]) by a commercial laboratory (BML Inc., Tokyo, Japan). The homeostasis model assessment ratio (HOMA-R) index, which indicates the state of insulin resistance, was calculated based on the IRI and FPG [15]. The body mass index (BMI) was calculated by dividing the body weight by the square of the height. Concentrations of urinary $\mathrm{N}$-acetyl$\beta$-D-glucosaminidase (NAG) and albumin, which indicate renal disease such as diabetes-associated nephropathy, were measured in the urine samples by the commercial laboratory (BML Inc.).

\section{Biochemical parameters}

Concentrations of total protein, albumin, bilirubin, aspartate aminotransferase (AST), alanine aminotransferase (ALT), alkaline phosphatase (ALP), lactate dehydrogenase (LDH), $\gamma$-glutamyl transpeptidase (GGT), urea nitrogen, creatinine, uric acid, IgG, IgM, IgA, IgD, low-density lipoprotein (LDL) cholesterol, high-density lipoprotein (HDL) cholesterol, and triglycerides in blood samples were measured by the commercial laboratory (BML Inc.).

\section{Measurement of tumor necrosis factor (TNF)- $a$ and high-sensitivity C-reactive protein (hs-CRP)}

The serum concentrations of TNF- $\alpha$ and hs-CRP were determined by enzyme-linked immunosorbent assay using commercially available kits for human TNF- $\alpha$ (Human TNF- $\alpha$ US, Invitrogen, Carlsbad, CA, USA) and human hs-CRP (C-Reactive Protein Kit, Hemagen Diagnostics, Waltham, MA, USA). All reagents and samples or standard solutions were added to a 96-well plate coated with murine monoclonal antibody against each protein and kept for $2 \mathrm{~h}$. After subsequent treatment for 1-2 h with alkaline phosphatase-conjugated polyclonal antibody, reaction with $p$-nitrophenyl phosphate was carried out for $20 \mathrm{~min}$. Trisodiumphosphate solution was then added to stop the reaction. The absorbance of each well was measured at $450 \mathrm{~nm}$, and the concentration of each protein was calculated from standard curves.

\section{Statistical analysis}

Statistical analyses were conducted using SPSS software (version 20.0; SPSS Japan, Tokyo, Japan). Differences between means at baseline and post-treatment were evaluated using the Wilcoxon signed-rank test. Spearman's rank correlation coefficient was used to evaluate correlations between clinical parameters. Differences were considered significant at $P \leq 0.05$.

\section{Results}

Table 1 shows the values of clinical parameters before and after periodontal treatment. The mean $P D, P D \geq 4 \mathrm{~mm}$, and BOP were significantly improved after non-surgical

Table 1 Periodontal parameters (mean \pm SD) at baseline and post-treatment

\begin{tabular}{llll}
\hline & Baseline & Post-Treatment & $P$ Value \\
\hline Mean PD (mm) & $4.26 \pm 1.26$ & $3.43 \pm 0.90$ & $0.005^{*}$ \\
PD $\geq 4$ mm (\%) & $48.1 \pm 30.4$ & $27.2 \pm 26.0$ & $0.005^{*}$ \\
BOP (\%) & $49.4 \pm 18.1$ & $22.3 \pm 19.8$ & $0.005^{*}$ \\
\hline
\end{tabular}

*Significant at $P \leq 0.05$ 
periodontal treatment. The periodontal treatment had no adverse effects.

The values of the systemic markers of T2DM are given in Table 2. The HbA1c level was significantly reduced after periodontal treatment. There was a tendency towards decreases in the levels of FPG, IRI, and HOMA-R, but these changes were not significant. There was little change in BMI. The levels of urinary NAG and albumin decreased significantly after treatment (Table 3 ).

While the changes were not significant for most of the biochemical parameters in the blood after the nonsurgical periodontal treatment, the reduction in the level of GGT was significant (Table 4). Although the change was not significant, periodontal treatment also tended to reduce the levels of AST, ALT, and LDH. The levels of urea nitrogen and creatinine tended to improve after treatment, but not significantly. The blood levels of total protein, albumin, bilirubin, and uric acid changed minimally after treatment. No significant changes were seen in immunoglobulins and lipid components after treatment. Although there was a slight decrease in the LDL cholesterol level and a slight increase in the HDL cholesterol level, the changes from baseline were not significant. Regarding the inflammatory biomarkers, the levels of TNF- $\alpha$ and hs-CRP were significantly decreased after periodontal treatment.

Table 5 presents the correlation analysis between clinical parameters that were significantly decreased after the periodontal treatment. Significant positive correlations were observed among mean $\mathrm{PD}, \mathrm{PD} \geq 4 \mathrm{~mm}$, and $\mathrm{BOP}$, and between urinary NAG and urinary albumin. In addition, $\mathrm{PD} \geq 4 \mathrm{~mm}$ showed a significant positive correlation with urinary albumin. Urinary NAG and albumin were significantly correlated with hs-CRP. Correlations between reductions in clinical parameters are shown in Table 6 . $\triangle$ Mean PD was significantly correlated with $\triangle \mathrm{PD} \geq 4 \mathrm{~mm}$. Furthermore, $\Delta$ mean $\mathrm{PD}$ and $\Delta \mathrm{PD} \geq 4 \mathrm{~mm}$ showed significant positive correlations with $\Delta \mathrm{TNF}-\alpha$.

\section{Discussion}

In the present study of T2DM patients, urinary NAG and albumin, which are markers of diabetic renal disease, decreased significantly after periodontal treatment.

Table 2 Diabetic parameters (mean \pm SD) at baseline and posttreatment

\begin{tabular}{llll}
\hline & Baseline & Post-Treatment & $P$ Value \\
\hline FPG $(\mathrm{mg} / \mathrm{dl})$ & $149.4 \pm 55.9$ & $117.2 \pm 17.6$ & 0.109 \\
IRI $(\mu \mathrm{U} / \mathrm{ml})$ & $6.5 \pm 2.9$ & $5.4 \pm 1.9$ & 0.110 \\
HOMA-R & $2.2 \pm 1.0$ & $1.4 \pm 0.7$ & 0.062 \\
$\mathrm{HbA1c}(\%)$ & $7.2 \pm 0.6$ & $6.8 \pm 0.6$ & $0.033^{*}$ \\
$\mathrm{BMI}\left(\mathrm{kg} / \mathrm{m}^{2}\right)$ & $24.5 \pm 2.3$ & $24.3 \pm 1.9$ & 0.838 \\
\hline
\end{tabular}

*Significant at $P \leq 0.05$
Table 3 Concentrations of NAG and albumin (mean \pm SD) in urine at baseline and post-treatment

\begin{tabular}{llll}
\hline & Baseline & Post-Treatment & $P$ Value \\
\hline Urinary NAG (U/l) & $8.1 \pm 4.3$ & $4.5 \pm 2.1$ & $0.005^{*}$ \\
Urinary albumin $(\mathrm{mg} / \mathrm{l})$ & $141.5 \pm 266.4$ & $51.7 \pm 108.8$ & $0.008^{*}$ \\
\hline
\end{tabular}

*Significant at $P \leq 0.05$

The serum levels of urea nitrogen and creatinine, which are markers of renal damage, also tended to improve after treatment. In addition, the concentration of urinary albumin was significantly correlated with $P D \geq 4 \mathrm{~mm}$ at baseline. Therefore, it was suggested that periodontal treatment in patients with T2DM might improve kidney function, directly or indirectly. A proposed mechanism for the effect of periodontitis on the development of renal disease is as follows. Individuals with significant periodontitis have chronic and recurrent episodes of low level bacteremia $[16,17]$. Circulating periodontal pathogens in the bloodstream could lead to renal endothelial damage. The lipopolysaccharide of periodontal pathogens may induce the secretion of inflammatory mediators, including interleukin 6 , TNF- $\alpha$, prostaglandin E2, and thromboxane B2. These cytokines accelerate atherogenesis, thrombus formation, and platelet aggregation [18]. Additionally, thromboxane has potent vasoconstrictive properties [19], and, speculatively, chronic production of

Table 4 Biochemical parameters (mean \pm SD) in blood at baseline and post-treatment

\begin{tabular}{|c|c|c|c|}
\hline & Baseline & Post-Treatment & $P$ Value \\
\hline Total protein (g/dl) & $7.0 \pm 0.7$ & $7.2 \pm 0.4$ & 0.624 \\
\hline Albumin $(\mathrm{g} / \mathrm{dl})$ & $4.3 \pm 0.3$ & $4.4 \pm 0.3$ & 0.552 \\
\hline Bilirubin (mg/dl) & $0.7 \pm 0.3$ & $0.7 \pm 0.3$ & 0.681 \\
\hline AST (U/I) & $23.3 \pm 5.5$ & $21.2 \pm 4.0$ & 0.165 \\
\hline $\mathrm{ALT}(\mathrm{U} / \mathrm{l})$ & $29.0 \pm 11.8$ & $23.2 \pm 6.3$ & 0.061 \\
\hline $\operatorname{ALP}(\mathrm{U} / \mathrm{l})$ & $163.0 \pm 61.8$ & $192.6 \pm 62.3$ & 0.051 \\
\hline LDH (U/I) & $300 \pm 113$ & $215 \pm 104$ & 0.060 \\
\hline GGT (U/l) & $33.4 \pm 19.6$ & $25.4 \pm 9.7$ & $0.025^{*}$ \\
\hline Urea nitrogen $(\mathrm{mg} / \mathrm{dl})$ & $16.5 \pm 4.5$ & $14.8 \pm 3.1$ & 0.424 \\
\hline Creatinine (mg/dl) & $0.90 \pm 0.20$ & $0.81 \pm 0.10$ & 0.053 \\
\hline Uric acid (mg/dl) & $4.78 \pm 0.90$ & $4.81 \pm 1.20$ & 0.723 \\
\hline $\operatorname{lgG}(\mathrm{mg} / \mathrm{dl})$ & $1303 \pm 290$ & $1231 \pm 223$ & 0.919 \\
\hline $\operatorname{lgM}(\mathrm{mg} / \mathrm{dl})$ & $104 \pm 38$ & $109 \pm 36$ & 0.610 \\
\hline $\lg \mathrm{A}(\mathrm{mg} / \mathrm{dl})$ & $337 \pm 72$ & $328 \pm 88$ & 0.859 \\
\hline $\operatorname{lgD}(\mathrm{mg} / \mathrm{dl})$ & $1.47 \pm 1.51$ & $1.71 \pm 2.16$ & 0.892 \\
\hline LDL cholesterol (mg/dl) & $113.7 \pm 24.0$ & $108.2 \pm 19.3$ & 0.814 \\
\hline HDL cholesterol (mg/dl) & $48.9 \pm 10.0$ & $51.8 \pm 16.9$ & 0.089 \\
\hline Triglycerides (mg/dl) & $97.1 \pm 51.3$ & $103.7 \pm 58.1$ & 0.695 \\
\hline TNF-a (pg/ml) & $4.89 \pm 4.98$ & $3.24 \pm 2.43$ & $0.026^{*}$ \\
\hline hs-CRP $(\mu \mathrm{g} / \mathrm{ml})$ & $1.30 \pm 3.33$ & $1.21 \pm 3.27$ & $0.021^{*}$ \\
\hline
\end{tabular}

*Significant at $P \leq 0.05$ 
Table 5 Correlation ( $r$ ) values between clinical parameters at baseline

\begin{tabular}{|c|c|c|c|c|c|c|c|c|}
\hline & Mean PD & $\mathrm{PD} \geq 4 \mathrm{~mm}$ & BOP & $\mathrm{HbA1c}$ & Urinary NAG & Urinary albumin & GGT & TNF-a \\
\hline $\mathrm{PD} \geq 4 \mathrm{~mm}$ & $0.878^{*}$ & & & & & & & \\
\hline BOP & $0.771^{*}$ & $0.608^{*}$ & & & & & & \\
\hline $\mathrm{HbA1c}$ & -0.152 & -0.325 & 0.138 & & & & & \\
\hline Urinary NAG & 0.464 & 0.501 & 0.389 & -0.24 & & & & \\
\hline Urinary albumin & 0.643 & $0.690^{*}$ & 0.631 & -0.109 & $0.726^{*}$ & & & \\
\hline GGT & -0.024 & 0.021 & -0.192 & -0.376 & 0.148 & 0.176 & & \\
\hline TNF-a & 0.379 & 0.393 & 0.021 & -0.210 & 0.359 & -0.052 & 0.243 & \\
\hline hs-CRP & 0.181 & 0.206 & 0.255 & -0.010 & $0.663^{*}$ & $0.827^{*}$ & 0.174 & -0.001 \\
\hline
\end{tabular}

*Significant at $P \leq 0.05$

this substance may lead to a chronic decrease in renal blood flow [12]. On the other hand, periodontal treatment may affect renal function indirectly. Diabetic renal disease is one of the diabetic complications. As a result of improved glycemic control by periodontal treatment, renal function may improve.

Although increased serum GGT activity is usually interpreted as a marker of alcohol abuse and liver dysfunction, parallel evidence from epidemiological studies suggests that higher serum GGT levels are also associated with the metabolic syndrome [20], hypertension [21], and diabetes [22, 23]. In the present study, the GGT level decreased after periodontal treatment. The levels of AST and ALT, which are also markers of liver damage, tended to decrease. Regarding periodontal diseases, there are few reports about GGT. It has been reported that GGT blood levels were positively associated with attachment level in alcoholic persons, but not in non-alcoholic persons [24]. On the other hand, there are some reports about a relationship between periodontal diseases and liver disease $[25,26]$. The present data appear to support such reports. There are two possible pathways for liver injury by periodontal disease, a direct pathway by periodontopathic bacteria and an indirect pathway by cytokines including TNF- $\alpha$ induced by bacteria and lipopolysaccharides. TNF- $\alpha$ plays a role in the pathogenesis of liver injury [27]. In the present study,
GGT might have improved due to blockage of these two pathways by periodontal treatment.

The good healing response of T2DM patients to nonsurgical therapy in the present study confirms the results of previous investigations $[28,29]$. The HbA1c level was significantly decreased after non-surgical periodontal treatment. The possible confounding factors may include changes in DM treatment and BMI during the study. However, since no changes were observed in them, this suggests that glycemic control might have been improved by periodontal therapy. Although periodontal therapy was performed for patients with T2DM whose HbA1c was $>10 \%$ in some studies, HbA1c levels should be controlled before periodontal therapy to avoid the risk of postoperative infection [30]. In this study, the HbA1c level was controlled to less than $8 \%$ to adapt to the clinical situation. The mean HbA1c at baseline was $7.2 \%$, which is lower than that in other studies. Nevertheless, it was noted that the diabetic parameters were significantly decreased.

In periodontitis, up-regulated proinflammatory cytokines contribute to periodontal tissue destruction [31]. It has been demonstrated that TNF- $\alpha$ has a role in osteoclastogenesis in mice [32], and recombinant TNF- $\alpha$ has been shown to accelerate periodontitis in rats [33]. TNF- $\alpha$ also induces insulin resistance in T2DM [34]. In addition, it has been shown that urinary TNF- $\alpha$ levels

Table 6 Correlation $(r)$ values between reductions in clinical parameters

\begin{tabular}{|c|c|c|c|c|c|c|c|c|}
\hline & $\triangle$ Mean PD & $\triangle P D \geq 4 \mathrm{~mm}$ & $\triangle \mathrm{BOP}$ & $\triangle \mathrm{HbA} 1 \mathrm{c}$ & $\triangle$ Urinary NAG & $\Delta$ Urinary albumin & $\Delta \mathrm{GGT}$ & $\triangle T N F-a$ \\
\hline$\triangle \mathrm{PD} \geq 4 \mathrm{~mm}$ & $0.730^{*}$ & & & & & & & \\
\hline$\triangle \mathrm{BOP}$ & 0.351 & 0.289 & & & & & & \\
\hline$\triangle \mathrm{HbA} 1 \mathrm{c}$ & -0.019 & -0.064 & 0.456 & & & & & \\
\hline$\triangle$ Urinary NAG & 0.522 & 0.24 & 0.224 & -0.313 & & & & \\
\hline$\Delta$ Urinary albumin & 0.328 & 0.178 & 0.134 & -0.142 & 0.599 & & & \\
\hline$\Delta \mathrm{GGT}$ & -0.508 & -0.317 & -0.246 & -0.506 & -0.116 & 0.108 & & \\
\hline$\Delta T N F-a$ & $0.677^{*}$ & $0.621^{*}$ & 0.309 & -0.223 & 0.407 & -0.146 & -0.012 & \\
\hline$\triangle \mathrm{hs}-\mathrm{CRP}$ & 0.081 & -0.007 & -0.054 & 0.136 & 0.341 & 0.403 & -0.212 & -0.018 \\
\hline
\end{tabular}

*Significant at $P \leq 0.05$ 
are associated with the presence and severity of microalbuminuria in patients with T2DM [35]. Thus, TNF- $\alpha$ appears to be a key mediator in the pathogenesis of periodontal disease, T2DM, and diabetic renal disease. In patients with periodontitis and T2DM, increased TNF- $\alpha$ levels are associated with increased attachment loss [36]. In the present study, serum TNF- $\alpha$ was shown to be significantly decreased by periodontal treatment. Furthermore, $\Delta$ mean $\mathrm{PD}$ and $\Delta \mathrm{PD} \geq 4 \mathrm{~mm}$ were significantly correlated with $\Delta \mathrm{TNF}-\alpha$. Therefore, it was suggested that periodontal treatment is effective in improving metabolic control in patients with T2DM, possibly through reduction in the serum concentration of TNF- $\alpha$ and decreased insulin resistance. Though some studies have shown improved glycemic control with periodontal treatment in T2DM patients through reduction of peripheral TNF- $\alpha$ concentrations $[37,38]$, no reduction in serum TNF- $\alpha$ levels has been found following periodontal therapy in T2DM patients in other studies [39, 40]. However, a recent systematic review found that periodontal treatment reduced serum levels of TNF- $\alpha$ and CRP in T2DM patients [41].

CRP, an important mediator of inflammation, is mainly synthesized in the liver. Elevated serum CRP is associated with both periodontitis [42, 43] and T2DM [44]. Meta-analyses and systematic reviews of the relationship of CRP to periodontitis have shown consistently higher CRP levels in patients than in controls $[42,43]$. In a meta-analysis of 4 randomized clinical trials [43], CRP levels were significantly reduced after the start of periodontal treatment. There is agreement between the findings of both meta-analyses and the results of the present study. In addition, the hs-CRP level was shown to be correlated with urinary NAG and albumin in the present study. A recent study showed that serum hs-CRP levels were associated with a subsequent risk of developing diabetic nephropathy in type 2 diabetic patients [45].

\section{Conclusion}

This pilot study showed that clinically successful nonsurgical periodontal treatment improved not only the level of glycemic control, but also the levels of NAG and albumin in the urine and GGT in the serum among various systemic disease markers. These findings suggest that periodontal treatment is effective not only in improving metabolic control, but also in reducing the risk of diabetic renal and liver disease in patients with T2DM. However, the present study has one limitation in that it lacked a group of T2DM patients who were not undergoing periodontal treatment; thus, how these patients would progress remains unknown. Another limitation was the small sample size. Thus, future studies of T2DM patients involving larger samples and a control group are needed to clarify how metabolic control and markers of diabetic liver and kidney diseases are affected by periodontal therapy.

\section{Abbreviations}

ALP: Alkaline phosphatase; ALT: Aminotransferase; AST: Aspartate aminotransferase; BMI: Body mass index; BOP: Bleeding on probing; FPG: Fasting plasma glucose; GGT: -glutamyl transpeptidase; HbA1c: Glycated hemoglobin; HDL: High-density lipoprotein; HOMA-R: Homeostasis model assessment ratio; hsCRP: High-sensitivity C-reactive protein; IRI: Immunoreactive insulin; LDH: Lactate dehydrogenase; LDL: Low-density lipoprotein; NAG: N-acetyl- $\beta-D-g l u c o s a m i n i d a s e$ PD: Probing depth; T2DM: Type 2 diabetes mellitus; TNF: Tumor necrosis factor

\section{Acknowledgements \\ N/A. \\ Funding \\ This study was supported in part by a Grant-in-Aid for Scientific Research (No. 17592163 and No. 26670894) from the Ministry of Education, Culture, Sports, Science and Technology-Japan. The authors report no conflicts of interest related to this study.}

\section{Availability of data and materials}

The raw data containing personal patient information are not publicly available due to confidentiality agreements with the participants.

\section{Authors' contributions}

$\mathrm{JH}$ was a major contributor in writing the manuscript. $\mathrm{JH}, \mathrm{HO}, \mathrm{KY}, \mathrm{JT}$, and $\mathrm{KS}$ performed the periodontal examinations and treatments. SG and AH performed the medical examinations. KH and TS measured the concentrations of TNF-a and hs-CRP. MI analyzed and interpreted the patient data. AH and KS designed the study. All authors read and approved the final manuscript.

\section{Competing interests}

The authors declare that they have no competing interests.

\section{Consent for publication}

Not applicable.

\section{Ethics approval and consent to participate}

All participants understood the nature of the research project and provided written, informed consent to participate in this study. Permission for this study was obtained from the Meikai University School of Dentistry Research Ethics Committee (approval No. 0207).

\section{Publisher's Note}

Springer Nature remains neutral with regard to jurisdictional claims in published maps and institutional affiliations.

\section{Author details}

${ }^{1}$ Division of Periodontology, Department of Oral Biology and Tissue Engineering, Meikai University School of Dentistry, 1-1 Keyakidai, Sakado-shi, Saitama-ken 350-0283, Japan. ${ }^{2}$ Meikai University School of Dentistry, Saitama-ken, Japan.

Received: 15 November 2016 Accepted: 12 April 2017

Published online: 21 April 2017

\section{References}

1. Chapple IL, Genco R. Diabetes and periodontal diseases: consensus report of the joint EFP/AAP workshop on periodontitis and systemic diseases. Periodontol. 2013;84(Suppl 4):S106-12.

2. Taylor GW, Burt BA, Becker MP, Genco RJ, Shlossman M, Knowler WC, et al. Non-insulin dependent diabetes mellitus and alveolar bone loss progression over 2 years. J Periodontol. 1998;69:76-83.

3. Borgnakke WS, Ylöstalo PV, Taylor GW, Genco RJ. Effect of periodontal disease on diabetes: systematic review of epidemiologic observational evidence. J Periodontol. 2013;84 Suppl 4:S153-69.

4. Grossi SG, Skrepcinski FB, DeCaro T, Robertson DC, Ho AW, Dunford RG, et al. Treatment of periodontal disease in diabetics reduces glycated hemoglobin. J Periodontol. 1997;68:713-9.

5. Sun WL, Chen LL, Zhang SZ, Wu YM, Ren YZ, Qin GM. Inflammatory cytokines, adiponectin, insulin resistance and metabolic control after periodontal intervention in patients with type 2 diabetes and chronic periodontitis. Intern Med. 2011;50:1569-74. 
6. Teshome A, Yitayeh A. The effect of periodontal therapy on glycemic control and fasting plasma glucose level in type 2 diabetic patients: systematic review and meta-analysis. BMC Oral Health. 2016;17:31.

7. Li Q, Hao S, Fang J, Xie J, Kong XH, Yang JX. Effect of non-surgical periodontal treatment on glycemic control of patients with diabetes: a meta-analysis of randomized controlled trials. Trials. 2015:16:291.

8. Engebretson SP, Hyman LG, Michalowicz BS, Schoenfeld ER, Gelato MC, Hou $W$, et al. The effect of nonsurgical periodontal therapy on hemoglobin A1C levels in persons with type 2 diabetes and chronic periodontitis: a randomized clinical trial. JAMA. 2013;310:2523-32.

9. Thorstensson H, Kuylenstierna J, Hugoson A. Medical status and complications in relation to periodontal disease experience in insulin-dependent diabetics. J Clin Periodontol. 1996;23:194-202.

10. Saremi A, Nelson RG, Tulloch-Reid M, Hanson RL, Sievers ML, Taylor GW, et al. Periodontal disease and mortality in type 2 diabetes. Diabetes Care. 2005;28:27-32.

11. Shultis WA, Weil EJ, Looker HC, Curtis JM, Shlossman M, Genco RJ, et al. Effect of periodontitis on overt nephropathy and end-stage renal disease in type 2 diabetes. Diabetes Care. 2007;30:306-11.

12. Kshirsagar AV, Moss KL, Elter JR, Beck JD, Offenbacher S, Falk RJ. Periodontal disease is associated with renal insufficiency in the Atherosclerosis Risk in Communities (ARIC) study. Am J Kidney Dis. 2005;45:650-7.

13. Armitage GC. Development of a classification system for periodontal diseases and conditions. Ann Periodontol. 1999;4:1-6.

14. Kashiwagi A, Kasuga M, Araki E, Oka Y, Hanafusa T, Ito H, et al. International clinical harmonization of glycated hemoglobin in Japan: From Japan Diabetes Society to National Glycohemoglobin Standardization Program values. J Diabetes Investig. 2012;3:39-40.

15. Matthews DR, Hosker JP, Rudenski AS, Naylor BA, Treacher DF, Turner RC. Homeostasis model assessment: insulin resistance and beta-cell function from fasting plasma glucose and insulin concentrations in man. Diabetologia. 1985;28:412-9.

16. Forner $L$, Larsen $T$, Kilian M, Holmstrup P. Incidence of bacteremia after chewing, tooth brushing and scaling in individuals with periodontal inflammation. J Clin Periodontol. 2006;33:401-7.

17. Iwai T. Periodontal bacteremia and various vascular diseases. J Periodontal Res. 2009;44:689-94.

18. Daugherty $A$, Webb NR, Rateri $D L$, King VL. Thematic review series: the immune system and atherogenesis. Cytokine regulation of macrophage functions in atherogenesis. J Lipid Res. 2005:46:1812-22.

19. Abuelo JG. Diagnosing vascular causes of renal failure. Ann Intern Med. 1995;123:601-14.

20. Rantala AO, Lilja M, Kauma H, Savolainen MJ, Reunanen A, Kesaniemi YA. Gamma-glutamyl transpeptidase and the metabolic syndrome. J Intern Med. 2000:248:230-8.

21. Lee DH, Ha MH, Kim JR, Gross M, Jacobs DR. Gammaglutamyltransferase, alcohol, and blood pressure. A four year follow-up study. Ann Epidemiol. 2002;12:90-6.

22. Lee DH, Ha MH, Kim JH, Christiani DC, Gross MD, Steffes M, et al. Gammaglutamyltransferase and diabetes-a 4 year follow-up study. Diabetologia. 2003:46:359-64.

23. Perry IJ, Wannamethee SG, Shaper AG. Prospective study of serum gammaglutamyltransferase and risk of NIDDM. Diabetes Care. 1998;21:732-7.

24. Khocht A, Janal M, Schleifer S, Keller S. The influence of gingival margin recession on loss of clinical attachment in alcohol-dependent patients without medical disorders. J Periodontol. 2003;74:485-93.

25. Ohyama H, Nakasho K, Yamanegi K, Noiri Y, Kuhara A, Kato-Kogoe N, et al. An unusual autopsy case of pyogenic liver abscess caused by periodontal bacteria. Jpn J Infect Dis. 2009;62:381-3.

26. Tomofuji T, Ekuni D, Sanbe T, Azuma T, Tamaki N, Irie K, et al. Effects of improvement in periodontal inflammation by toothbrushing on serum lipopolysaccharide concentration and liver injury in rats. Acta Odontol Scand. 2009;67:200-5

27. Bradham CA, Plümpe J, Manns MP, Brenner DA, Trautwein C. Mechanisms of hepatic toxicity. I. TNF-induced liver injury. Am J Physiol. 1998;275:G387-92

28. Tervonen $T$, Knuuttlia M, Pohjamo L, Nurkkala H. Immediate response to nonsurgical periodontal treatment in subjects with diabetes mellitus. J Clin Periodontol. 1991:18:65-8.

29. Westfelt $E$, Rylander H, Blohme G, Jonasson P, Lindhe J. The effect of periodontal therapy in diabetics Results after 5 years. J Clin Periodontol. 1996;23:92-100.
30. Wong TY. A nationwide survey of deaths from oral and maxillofacial infections: the Taiwanese experience. J Oral Maxillofac Surg. 1999:57:1297-9.

31. Graves DT, Cochran D. The contribution of interleukin-1 and tumor necrosis factor to periodontal tissue destruction. J Periodontol. 2003;74:391-401.

32. Graves DT, Oskoui M, Volejnikova S, Naguib G, Cai S, Desta T, et al. Tumor necrosis factor modulates fibroblast apoptosis, PMN recruitment, and osteoclast formation in response to $P$. gingivalis infection. J Periodontal Res. 2001;80:1875-9.

33. Gaspersic R, Stiblar-Martincic D, Osredkar J, Skaleric U. Influence of subcutaneous administration of recombinant TNF-alpha on ligature-induced periodontitis in rats. J Dent Res. 2003:38:198-203.

34. Khosravi R, Ka K, Huang T, Khalili S, Nguyen BH, Nicolau B, et al. Tumor necrosis factor- $a$ and interleukin-6: potential interorgan inflammatory mediators contributing to destructive periodontal disease in obesity or metabolic syndrome. Mediators Inflamm. 2013. doi: 10.1155/2013/728987.

35. Lampropoulou IT, Stangou M, Papagianni A, Didangelos T, lliadis F, Efstratiadis G. TNF-a and microalbuminuria in patients with type 2 diabetes mellitus. J Diabetes Res. 2014; doi: 10.1155/2014/394206.

36. Engebretson S, Chertog R, Nichols A, Hey-Hadavi J, Celenti R, Grbic J. Plasma levels of tumour necrosis factor-alpha in patients with chronic periodontitis and type 2 diabetes. J Clin Periodontol. 2007;34:18-24.

37. Iwamoto $Y$, Nishimura F, Nakagawa M, Sugimoto H, Shikata $K$, Makino H, et al. The effect of antimicrobial periodontal treatment on circulating tumor necrosis factor-alpha and glycated hemoglobin level in patients with type 2 diabetes. J Periodontol. 2001;72:774-8.

38. Dağ A, Firat ET, Arikan S, Kadiroğlu AK, Kaplan A. The effect of periodontal therapy on serum TNF-alpha and HbA1C levels in type 2 diabetic patients. Aust Dent J. 2009;54:17-22

39. Kardeşler L, Buduneli N, Cetinkalp S, Kinane DF. Adipokines and inflammatory mediators after initial periodontal treatment in patients with type 2 diabetes and chronic periodontitis. J Periodontol. 2010;81:24-33.

40. Chen L, Luo G, Xuan D, Wei B, Liu F, Li J, et al. Effects of non-surgical periodontal treatment on clinical response, serum inflammatory parameters, and metabolic control in patients with type 2 diabetes: a randomized study. J Periodontol. 2012;83:435-43.

41. Artese HP, Foz AM, Rabelo Mde S, Gomes GH, Orlandi M, Suvan J, et al. Periodontal therapy and systemic inflammation in type 2 diabetes mellitus: a meta-analysis. PLoS One. 2015; doi: 10.1371/journal.pone.0128344.

42. Paraskevas S, Huizinga JD, Loos BG. A systematic review and meta-analyses on C-reactive protein in relation to periodontitis. J Clin Periodontol. 2008;35:277-90.

43. Freitas CO, Gomes-Filho IS, Naves RC. Nogueira Filho Gda R, Cruz SS, Santos CA. Influence of periodontal therapy on C-reactive protein level: a systematic review and meta-analysis. J Appl Oral Sci. 2012;20:1-8.

44. Gelaye B, Revilla L, Lopez T, Suarez L, Sanchez SE, Hevner K, et al. Association between insulin resistance and c-reactive protein among Peruvian adults. Diabetol Metab Syndr. 2010;2:30. doi:10.1186/1758-5996-2-30.

45. Hayashino Y, Mashitani T, Tsujii S, Ishii H. Serum high-sensitivity C-reactive protein levels are associated with high risk of development, not progression, of diabetic nephropathy among Japanese type 2 diabetic patients: a prospective cohort study (Diabetes Distress and Care Registry at Tenri [DDCRT7]). Diabetes Care. 2014;37:2947-52.

\section{Submit your next manuscript to BioMed Central and we will help you at every step:}

- We accept pre-submission inquiries

- Our selector tool helps you to find the most relevant journal

- We provide round the clock customer support

- Convenient online submission

- Thorough peer review

- Inclusion in PubMed and all major indexing services

- Maximum visibility for your research

Submit your manuscript at www.biomedcentral.com/submit 